DOI: $10.2478 / \mathrm{v} \cdot 10169-012-0024-\mathrm{x}$

\title{
EFFECT OF INITIAL POROSITY ON MATERIAL RESPONSE UNDER MULTI-AXIAL STRESS STATE FOR S235JR STEEL
}

\author{
P.G. KOSSAKOWSKI ${ }^{1}$
}

\begin{abstract}
The effect of the initial porosity on the material response under multi-axial stress state for S235JR steel using the Gurson-Tvergaard-Needleman (GTN) material model was examined. Three levels of initial porosity, defined by the void volume fraction $f_{0}$, were considered: zero porosity for fully dense material without pores, average and maximum porosity according to the metallurgical requirements for S235JR steel. The effect of the initial porosity on the material response was noticed for tensile elements under multi-axial stress state defined by high stress triaxiality $\sigma_{m} / \sigma_{e}=1.345$. This effect was especially noticeable at the range of the material failure. In terms of the load-bearing capacity of the elements, the conservative results were obtained when maximum value of $f_{0}=0.0024$ was used for S235JR steel under multi-axial stress state, and this value is recommended to use in the calculations in order to preserve the highest safety level of the structure. In usual engineering calculations, the average porosity defined by $f_{0}=0.001$ may be applied for S235JR.
\end{abstract}

Key words: Initial porosity, initial void volume fraction $f_{0}$, Gurson-Tvergaard-Needleman material model, multi-axial stress states, high stress triaxiality, voids, numerical calculations, S235JR steel.

\section{INTRODUCTION}

The load-bearing capacity of the steel structures in a long term of the operation may be significantly reduced due to many factors. In the extreme situation, the structure is subjected to the pre-failure condition, which finally may lead to a catastrophe. Thus, it is still necessary to analyse such situations and develop methods of estimation of the limit loads beyond the elastic range. It should be noticed that this problem is a subject of studies related to the load-bearing capacity $[1,2]$ and the stability of structures [3-5], damage detection [6, 7] and numerical methods used in such analyses [8].

There are many damages detected in structural elements operating under pre-failure conditions. Mostly, these are cracks, holes, and other material discontinuities. In Fig. 1, a damage in the form of the material structure discontinuities formed due to a phenomenon such as corrosion is shown. In the region of this hole, the strain-stress state

${ }^{1}$ Chair of Strength of Materials and Concrete Structures, Faculty of Civil Engineering and Architecture, Kielce University of Technology, Kielce, Poland, e-mail: kossak@tu.kielce.pl 
is subjected to certain modification that may be dangerous for particular element and whole structure.

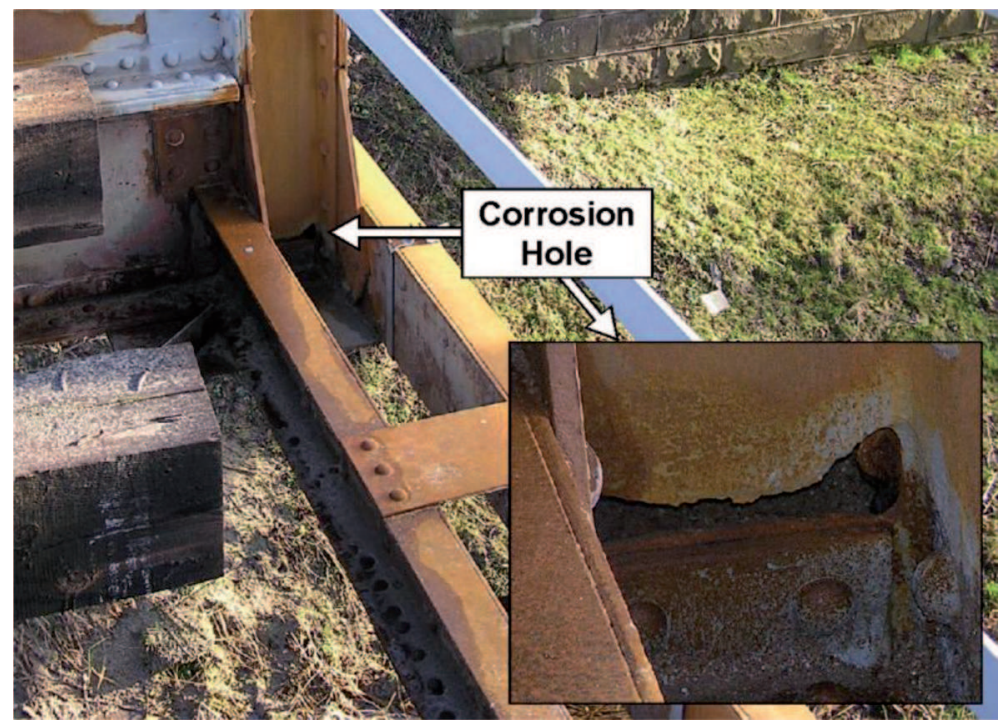

Fig. 1. Damage due to corrosion in structural element of a bridge.

In the situation analysed, the material is subjected to a completely different stress state than those assumed, which may cause the transition of the material in a non-linear operating range, above the yield stress. In an extreme case so far negligible stress components can reach high values, leading to the change of the existing stress state, from uniaxial to multi-axial. It may induce the destruction of the element, and ultimately failure of the entire supporting structure. Thus, in the case of the pre-failure conditions the analysis of multi-axial stress states, defined by all stress components, is an important issue from practical point of view.

Experimental studies of multi-axial stress states are often carried out by means of a tensile bar of circular cross-section with the circumferential annular notch (Fig. 2).

This is a kind of a model element, in which the so-called neck is occurred as a result of a plasticity. In contrast to the smooth specimen, which is subjected to uniaxial stress state, in the sample with a notch it is possible to force the initial stress state by choosing a suitable geometry, in particular, the depth of a notch. Spatial stress state is determined by the so-called stress triaxiality $\sigma_{m} / \sigma_{e}$, i.e. the ratio of mean normal stress $\sigma_{m}$ to effective stress $\sigma_{e}$. For the notched specimen, the stress triaxiality $\sigma_{m} / \sigma_{e}$ may be estimated by using the BRIDGMan solution [9]. According to that solution, the stress triaxiality $\sigma_{m} / \sigma_{e}$ for the middle plane of the notch is described by following relation 

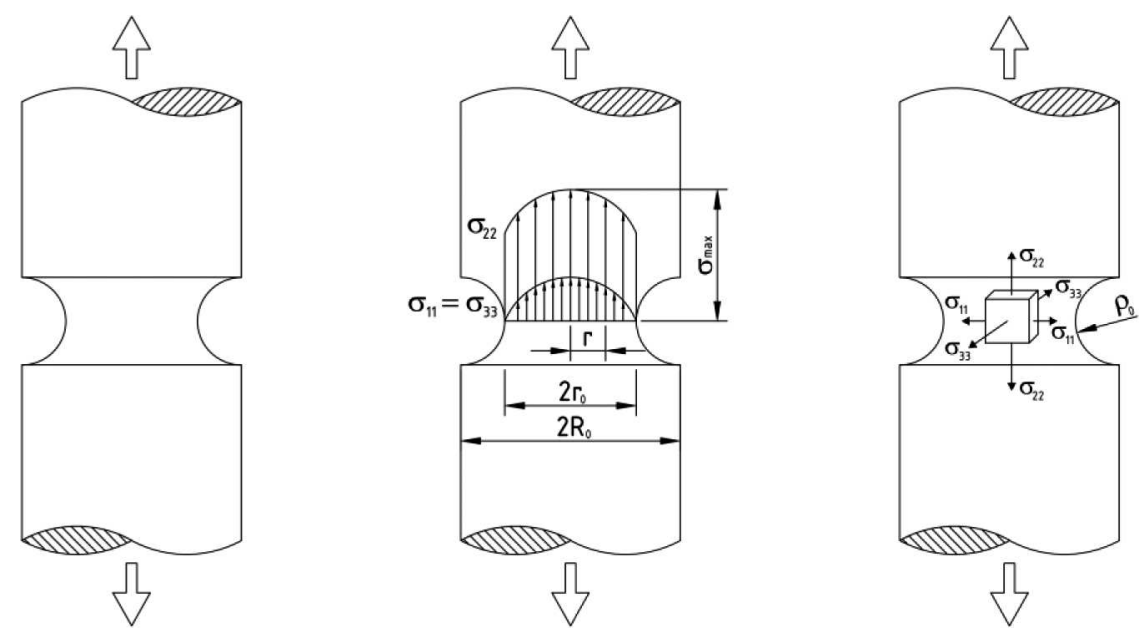

Fig. 2. Stress state components under multi-axial stress state in a circular cross-sectional notched specimen.

$$
\frac{\sigma_{m}}{\sigma_{e}}=\frac{1}{3}+\ln \left(\frac{r_{0}}{2 \rho_{0}}+1\right)
$$

where: $\sigma_{m}=\left(\sigma_{11}+\sigma_{22}+\sigma_{33}\right) / 3$ - mean normal stress, $\sigma_{e}$ - effective stress, $r_{0}-$ initial minimal radius, $\rho_{0}-$ initial notch radius.

As can be seen, when multi-axial stress states are involved, i.e. when the failure stress is a three-stress function, the strength analysis becomes more complicated. In the situation of damaged elements which are plastically deformed, the classical strength hypotheses such as Huber-Mises-Hencky (HMH) hypothesis cannot be used due to assumption that the continuum of the material structure. It is necessary to apply the damage material model taking into account the influence of structural defects on the material strength.

Damage of the structure of metallic materials is connected with processes occurring at microstructural level. It is related to the development of micro-voids formed in both the material matrix and the existing non-metallic inclusions and second-phase particles. In shear and ductile fracture, the cracking is attributable to the nucleation, growth and coalescence of voids. The growth and coalescence of voids are the most important step in a damage mechanism, resulting in the development of localised plastic deformations (Fig. 3).

Phenomena described above can be analysed and simulated by using damage models in which the relationship between the particular failure stages and the strength of the material is defined. The GuRson material model [10] for a porous solid was one of the first advanced damage material model, which takes into consideration the influence of micro-defects on the material strength. The original GuRson criterion [10] included 


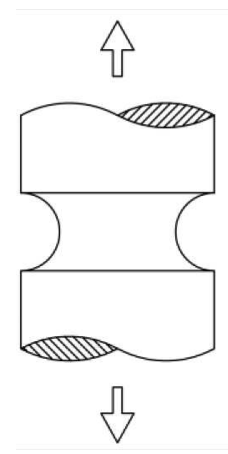

a)

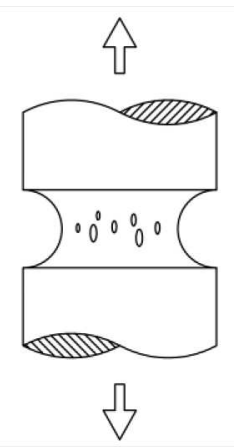

b)

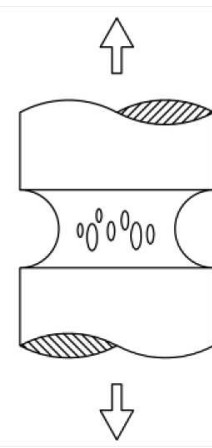

c)

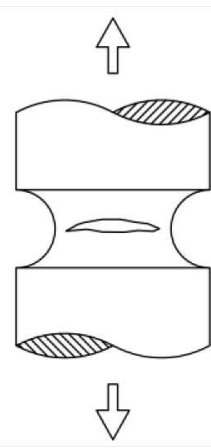

d)

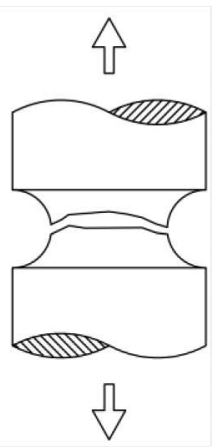

e)

Fig. 3. Micro-mechanism of ductile fracture under multi-axial stress state: a) notched tensile element, b) void nucleation, c) void growth, d) void coalescence leading to form a crack, e) failure.

in the Huber-Mises-Hencky yield function of the influence of microdamage (pores, voids) on the material strength by assuming that the proportion of voids in the plastic potential function was dependent on the void volume fraction $f$. The original Gurson model was modified later by many authors, and the Gurson-TvergaARD-NEEDLEMAN (GTN) material model is the most common and developed its form. Taking into consideration the subsequent modifications by Tvergaard [11], Tvergaard and Needleman [12] and Needleman and TvergaARd [13], the yield criterion according to the GTN model is described as

$$
\Phi=\left(\frac{\sigma_{e}}{\sigma_{0}}\right)^{2}+2 q_{1} f^{*} \cosh \left(q_{2} \frac{3 \sigma_{m}}{2 \sigma_{0}}\right)-\left(1+q_{3} f^{* 2}\right)=0
$$

where: $\sigma_{e}$ - effective stress, $\sigma_{0}$ - yield stress, $\sigma_{m}$ - hydrostatic pressure (mean stress), $f^{*}$ - modified void volume fraction, $q_{i}$ - TvergaARD's parameters.

The modified void volume fraction $f^{*}$ is defined as follows:

$$
f^{*}=\left\{\begin{array}{lll}
f & \text { for } \quad f \leq f_{c} \\
f_{c}+\frac{\bar{f}_{F}-f_{c}}{f_{F}-f_{c}}\left(f-f_{c}\right) & \text { for } \quad f_{c}<f<f_{F} \\
\bar{f}_{F} & \text { for } \quad f \geq f_{F}
\end{array}\right.
$$

where: $f_{c}$ - critical void volume fraction at which the void coalescence starts, $f_{F}$ - void volume fraction corresponding to the complete loss of the material strength, $\bar{f}_{F}=\left(q_{1}+\sqrt{q_{1}^{2}-q_{3}}\right) / q_{3}$.

As can be seen, for non-deformed material, the void volume fraction $f *(V V F)$ is equal to the initial void volume fraction $f_{0}$, which strictly defines the initial material porosity. 
An increase in the void volume fraction $\dot{f}$ is defined by relationship:

$$
\dot{f}=\dot{f}_{g r}+\dot{f}_{\text {nucl }}=(1-f) \dot{\boldsymbol{\varepsilon}}^{p l}: \mathbf{I}+\frac{f_{N}}{s_{N} \sqrt{2 \pi}} \exp \left[-\frac{1}{2}\left(\frac{\varepsilon_{e m}^{p l}-\varepsilon_{N}}{s_{N}}\right)^{2}\right] \cdot \dot{\varepsilon}_{e m}^{p l}
$$

where: $\dot{f}_{g r}$ - change due to growth of voids existing in the material, $\dot{f}_{n u c l}-$ change due to nucleation of new voids, $f_{N}$ - volume fraction of nucleated voids, $s_{N}-$ standard deviation of nucleation strain, $\dot{\boldsymbol{\varepsilon}}^{p l}$ - plastic strain rate tensor, I - second-order unit tensor, $\varepsilon_{N}$ - mean strain of the void nucleation, $\varepsilon_{e m}^{p l}$ - equivalent plastic strain in the matrix material, $\dot{\varepsilon}_{e m}^{p l}$ - equivalent plastic strain rate in the matrix material.

The GTN material model is implemented in many computational programs and used in strength analysis of materials commonly used in many engineering sectors. Due to the significant capabilities in practical applications, the current standards obligatory in European Union, for instance PN-EN 1993-1-10:2007 [14] and its commentary [15], recommend to use the GTN material model in analysis of pre-failure condition for building structures. The GTN model ensures good consistency of the results obtained numerically and experimentally and what is the most important, enables complete analysis of capacity of the structure up to the total failure of the elements, eg. [16-19].

The GTN material model seems to be very useful in practical analysis of loadbearing capacity of the metal building construction and may be applied in analysis of the pre-failure conditions and estimation of the limit loads beyond the elastic range. Taking this into consideration, a research program was initiated to elaborate procedures which allow to simulate numerically the load-bearing capacity of the steel building construction elements made of S235JR steel which may operate in pre-failure states basing on the GTN material model. Taking into account the problems connected with application of the GTN material model in the engineering issues, especially the lack of the microstructural parameters for steels used most commonly in civil engineering, the standardisation of the GTN material parameters for S235JR steel is one of the main part of the research program. Because S235JR steel is the main steel grade used in civil engineering in Poland and other European countries, it seems, that the results obtained will be helpful in analysis and expert opinions on the load-bearing capacity of steel components and structures made of this steel grade.

In this study a basic GTN material model parameter, such as initial void volume fraction $f_{0}$, which corresponds to the material porosity, was analysed for S235JR steel. The influence of initial porosity on the material response was examined. Several values of initial void volume fractions $f_{0}$ for S235JR steel were tested, assuming the fully dense material without pores and typical or maximum values of $f_{0}$ in order to analyse the porosity effect. The multi-axial stress state was considered for tensile notched elements with initial stress triaxiality $\sigma_{m} / \sigma_{e}>1$, as complementary to the study on the porosity effect in S235JR steel at low stress triaxiality [20]. The analysis was focused on the load-bearing capacity of the elements in relation to the void volume fraction $V V F$ changes. 
It seems that phenomena observed for S235JR steel may occur in other steel grades with similar porosity and metallurgical composition, thus the results obtained may be useful for steel grades used in civil engineering and technique.

\section{SCOPE OF ANALYSIS}

As mentioned before, the presented study concerned the influence of the initial porosity on the S235JR steel response under multi-axial stress state. The elements with a circular cross-section subjected to static tension for initial stress triaxiality $\sigma_{m} / \sigma_{e}>1$ were considered. The analysis was performed in several steps, including microstructural examinations, experimental tests and numerical calculations. The modified GTN material model was assumed for tested elements, according to the criterion (1.2). In subsequent steps of the analysis, the material parameters such as elastic-plastic model, TVERGAARD's parameters and GTN material parameters were determined for tested steel. Finally, the analysis of the influence of initial void volume fraction $f_{0}$ on the material response under multi-axial stress state for S235JR steel was performed.

\section{INITIAL VOID VOLUME FRACTION $f_{0}$ FOR S235JR STEEL}

In order to examine the influence of the initial porosity on S235JR steel response, the initial void volume fraction $f_{0}$ was assumed for extreme situations, similarly as in the study conducted by Kossakowski [20]. The fully dense material without pores and average and maximum porosity of S235JR steel were assumed.

For the fully dense material the initial porosity is zero, and consequently the initial void volume fraction was assumed as $f_{0}=0$ for the tested material.

In order to estimate average porosity of S235JR steel, the microstructural examinations were performed and images of microstructure with a ferritic-perlitic matrix were obtained (Fig. 4).

The non-metallic inclusions, mainly sulfides and brittle oxides were reported. In order to fully characterize non-metallic inclusions in the material the basic stereological parameters were determined. The porosity of S235JR steel was different for various parts in longitudinal and central cross-sections of the specimens. The average initial void volume fraction was determined as $f_{0}=0.001$ for S235JR steel [20].

The maximum value of initial porosity for S235JR steel was determined basing on assumptions, that the material contains non-metallic inclusions of sulphur and manganese. The maximum initial void volume fraction $f_{0}$ was estimated using FrankLIN's formulae [21]:

$$
f_{0}=0.054\left(S \%-\frac{0.001}{M n \%}\right)
$$

where: $S, M n$ - proportional content of sulphur and manganese inclusions. 


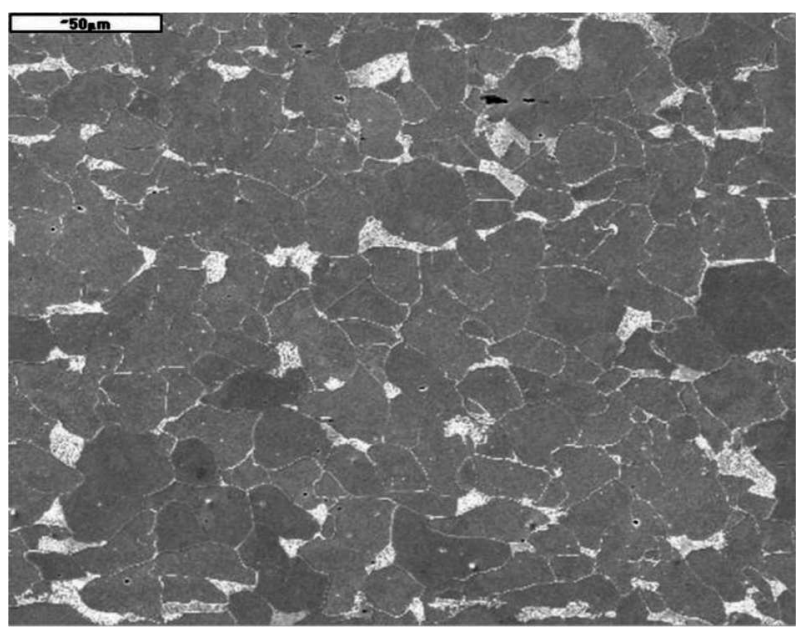

Fig. 4. SEM image of S235JR steel.

The maximum content of sulphur and manganese for S235JR steel was assumed according to the metallurgical requirements given in PN-EN 10025-1:2005 [22] as $M n=1.5 \%$ and $S=0.045 \%$. For such content of inclusions, the maximum initial void volume fraction for S235JR was determined as $f_{0}=0.0024$ [20] according to the formulae (3.1).

\section{GTN MATERIAL PARAMETERS FOR S235JR STEEL}

In order to determine GTN material parameters for S235JR steel, the combined experimental-numerical method was applied basing on the studies conducted by KossaKowsKI [16, 18, 19] and KossaKowsKi and TrąMPCZYŃsKi [17].

The strength parameters and the elastic-plastic model were elaborated for S235JR steel in the first step. The standard static tensile strength tests were performed, according to PN-EN10002-1:2004 [23] using the unnotched specimens with a circular cross-section of nominal diameter $d=10 \mathrm{~mm}$, the length of the measuring base $l_{0}=50 \mathrm{~mm}$, and the primary cross-sectional area $S_{0}=78.5 \mathrm{~mm}^{2}$. The following average strength properties were obtained during the tests: yield stress $\sigma_{0}=318 \mathrm{MPa}$, tensile strength $R_{m}=446 \mathrm{MPa}$ and displacement percentage $A_{5}=33.9 \%$. The nominal strength curves $\sigma(\varepsilon)$, where $\sigma$ denotes normal stress, and $\varepsilon$ denotes the longitudinal strain, were determined for S235JR steel. 
The elastic-plastic model for S235JR steel was described by approximation curve $\sigma(\varepsilon)$ as $[16,17,19]$

$$
\begin{array}{llll}
\sigma=E \varepsilon & \text { for } & \sigma<\sigma_{0} \\
\frac{\sigma}{\sigma_{0}}=\left(\frac{\sigma}{\sigma_{0}}+\frac{3 G}{\sigma_{0}} \varepsilon_{e m}^{p l}\right)^{N} & \text { for } & \sigma \geq \sigma_{0}
\end{array}
$$

where: $\sigma$ - stress, $\sigma_{0}$ - yield stress, $\varepsilon_{e m}^{p l}$ - equivalent plastic strain in the matrix material, $G$ - coefficient of transverse elasticity, $G=80 \mathrm{GPa}, N$ - strain-hardening exponent, $N=0.183$.

In the next step the essential GTN material model parameters were determined for S235JR steel, basing on the results obtained by Kossakowski [16, 18, 19] and Kossakowski and TrĄMPCZYŃski [17].

The average initial void volume fraction was assumed as $f_{0}=0.001$, according to the results described in Paragraph 3.

TVERGAARD's parameters for tested material were determined basing on the results obtained by FalesKog et al. [24]. In relation of the ratio $\sigma_{0} / E=0.00155$ and strain-hardening exponent $N=0.183$, the values of TVERGAARD's parameters were established as $q_{1}=1.90, q_{2}=0.81$ and $q_{3}=3.61$.

A combination of the experimental and numerical methods was used to determine the other GTN material parameters for S235JR. Using a program based on the Finite Element Method, Abaqus Explicit version 6.10, the experimental tensile tests were modelled numerically. Basing on the $\sigma(\varepsilon)$ curves obtained during experimental tests, the GTN material parameters were changed within certain limits iteratively using the optimization criterion based on the convergence of the $\sigma(\varepsilon)$ values obtained numerically and experimentally.

The critical void volume fraction $f_{c}$ was determined as $f_{c}=0.06$. In order to analyse whole failure range and minimize the softening effect, the critical void volume fraction corresponding to the complete loss of material strength was assumed as $f_{F}=0.667$. The volume fraction of the nucleated voids was established as $f_{N}=0.04$, the average nucleation strain was $\varepsilon_{N}=0.30$ and the standard deviation of the nucleation strain was $s_{N}=0.05$. All the GTN parameters for S235JR steel are summarized in Table 1.

Table 1

Microstructural parameters of the GTN model of S235JR steel.

\begin{tabular}{|c|c|c|c|c|c|c|c|c|}
\hline$f_{0}$ & $f_{c}$ & $f_{F}$ & $q_{1}$ & $q_{2}$ & $q_{3}$ & $\varepsilon_{N}$ & $f_{N}$ & $s_{N}$ \\
\hline 0.0000 & 0.0010 & 0.667 & 1.90 & 0.81 & 3.61 & 0.3 & 0.04 & 0.05 \\
0.0024 & & & & & & & & \\
\hline
\end{tabular}




\section{Strength tests OF TENSILE ELEMENTS AT HIGH STRESS TRIAXIALITY}

The tensile elements with circular cross-sections for different notch radii $\rho_{0}$ were tested during a wide research program $[16,17,19]$. In this study the multi-axial stress state was realized for elements with high initial stress triaxiality. The elements with diameter of $2 R_{0}=14.0 \mathrm{~mm}$ and $2 r_{0}=7.0 \mathrm{~mm}$ and the notch radius $\rho_{0}=1.0 \mathrm{~mm}$ were tested according to the geometry shown in Fig. 5a. It allowed to obtain multi-axial state of stress corresponding to the initial stress triaxiality $\sigma_{m} / \sigma_{e}=1.345$. The experiments included standard static tensile strength tests. The load $F$ and displacement of points distributed symmetrically along the notch $l$, were measured with the extensometer of the initial length of $32.56 \mathrm{~mm}$ (Fig. 5b).

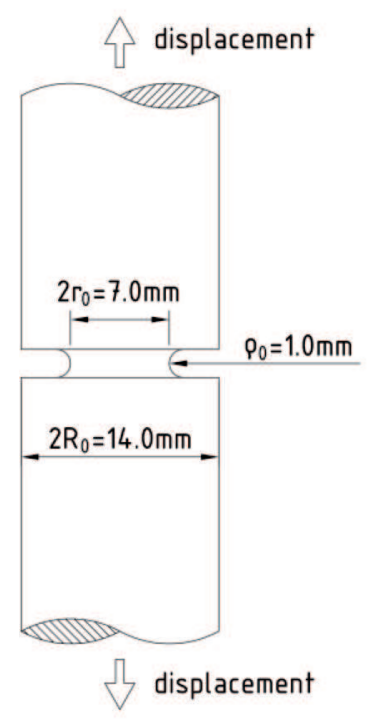

a)

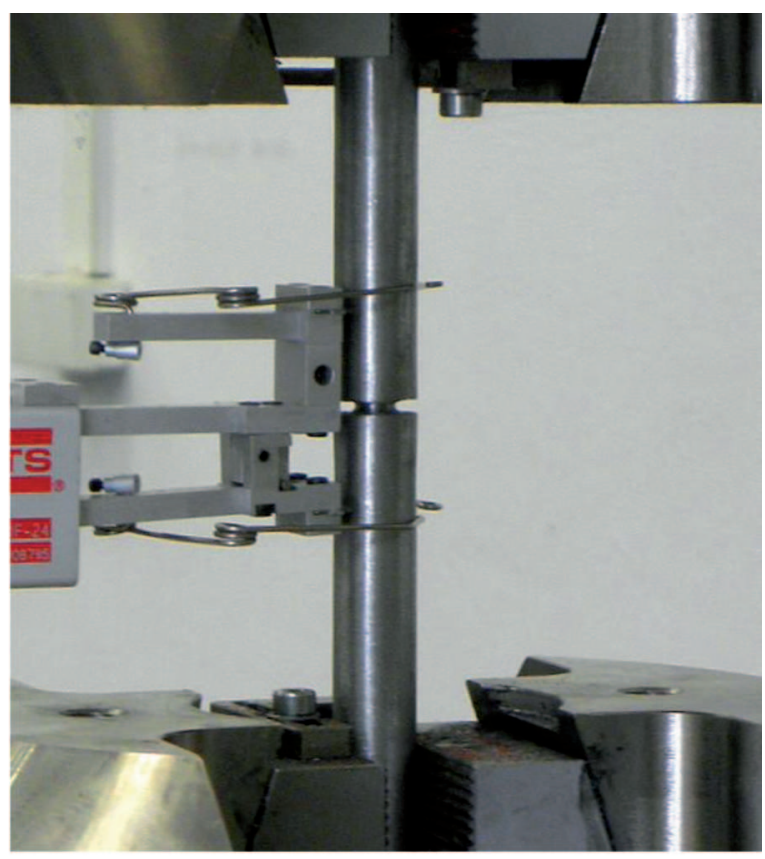

b)

Fig. 5. Ring-notched round specimen subjected to tension under multi-axial stress state: geometry of specimen (a); test stand (b).

6. Analysis of EFFect of Initial void volume fRaction $f_{0}$ on S235JR STEEL RESPONSE AT HIGH STRESS TRIAXIALITY

The influence of the initial porosity defined by initial void volume fraction $f_{0}$ on S235JR steel response was examined by numerical simulations of tensile tests of not- 
ched specimens, which were described in previous section. The numerical analysis was performed using Abaqus version 6.10 program [25].

The samples of circular cross section with a ring notch radius $\rho_{0}=1.0 \mathrm{~mm}$ were modelled and subjected to static tension at a controlled rate of displacement $4 \mathrm{~mm} / \mathrm{min}$, similarly as in the experiments. Due to the symmetry of the problem, only half of the samples were modelled using the standard 4-nodal CAX4R elements. The Gurson-Tvergaard-Needleman (GTN) material model was applied for models considered with using a nonlinear dynamic analysis Explicit module.

Taking into consideration the problems, which are observed during numerical simulations conducted with using damage material models, such as the mesh-size effect and the softening phenomenon, and recommendations for such analyses [18, 24, 26-28], two approaches, non-local and local, were applied. In the first, non-local method, the GTN material model for porous solids was assumed for the whole numerical model and this model is referred as GTN. In the second, local model, referred as Cell, only the elements adjacent to the crack plane were modelled with using the GTN material model. For the rest of the numerical model the elastic-plastic material model was assumed. Figure 6 shows a scheme of GTN and Cell numerical models.

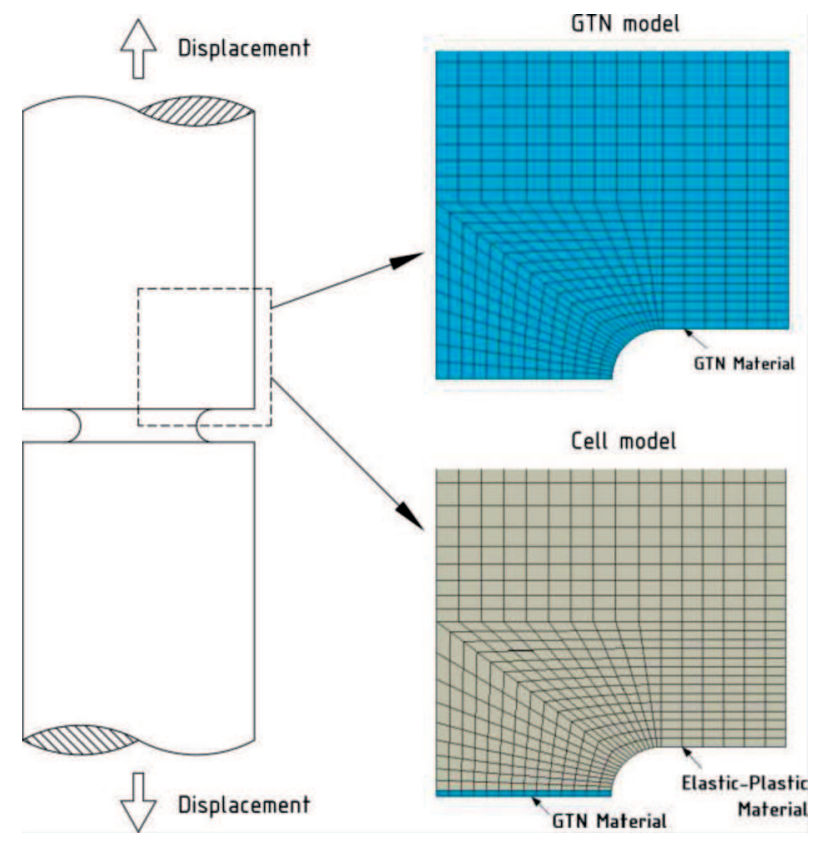

Fig. 6. Scheme of GTN and Cell numerical models.

In order to minimize mesh size effect and softening phenomenon, the microstructurally-based length scales methods were used in numerical modelling for both models shown in Fig. 6. Length scales methods are based on the fracture criterion which is 
satisfied over a minimum volume of material, defined in two dimensions by a characteristic length measure $l_{c}$ in the region of high stresses and plastic strain in order to form a macroscopic crack [29]. In presented study HANCock and MAcKENZIE method [30] was used. According to this approach, the length scale is represented by the size of inclusion colonies, which are visible in a fractograph. The fracture is connected with linking of holes formed from coalescing inclusion colonies and the macrocrack formation only occurs when shear localizes between multiple clusters. The void growth expands the cluster of inclusion colonies.

In the study, the characteristic length $l_{c}$ was defined as the dimensions of plateaus and valleys measured on the fracture surface. According to the results of analysis performed by Kossakowsкi [18], the average characteristic length $l_{c}$ was determined as $l_{c} \approx 250 \mu \mathrm{m}$. The mesh in the region close to the fracture plane, the so-called process zone, was modelled basing on the determined characteristic length $l_{c}$. For GTN model the finite elements width $D$ was equal to characteristic length $l_{c}=250 \mu \mathrm{m}$, while the height of the finite elements was different, as it is shown in Figure 6. In the case of application of Cell model the mesh size of the separate layer corresponding to the process zone was $D \times D / 2$, where $D$ was equal to the characteristic length $l_{c}=250 \mu \mathrm{m}$.

In the last stage of the study, the analysis of the influence of initial porosity on the material response under multi-axial stress state for S235JR was performed. It was based on the analysis of the force-elongation $F(l)$ curves determined during experiments and numerical simulations (Figs. 7 and 8) and the changes of void volume fraction VVF obtained numerically (Figs. 9 and 10) for the GTN material parameters assumed according to Table 1 .

As can be seen in Figures 7 and 8 the tensile strength curves obtained by applying both GTN and Cell models were consistent with the experimental results in the middle range of deformation, when the maximum force $F$ was reached. In the next range, from the maximum force up to the failure the differences revealed, depending on the numerical model used.

In the case of application of the GTN model, the slight softening phenomenon was noticed in the range above the maximum force $F$, which corresponded to elongation $l$ $>0.5 \mathrm{~mm}$. Above that point, when GTN model was applied, the forces $F$ determined numerically were lower than those obtained during experiments.

The reverse phenomenon was observed when Cell model was applied. In the range above the maximum force $F$, which corresponded to elongation $l>0.52 \mathrm{~mm}$ the forces $F$ determined numerically were higher than those obtained during experiments.

Summing up, the force-elongation $F(l)$ curves obtained numerically for assumed three initial void volume fraction $f_{0}$ were different for both GTN and Cell models in comparison to those determined during experiments at the failure range. For both the models the highest values of forces were noticed when the fully dense material without pores was considered with initial void volume fraction $f_{0}=0$, and the lowest values of force were noticed for maximum porosity defined by $f_{0}=0.0024$. 


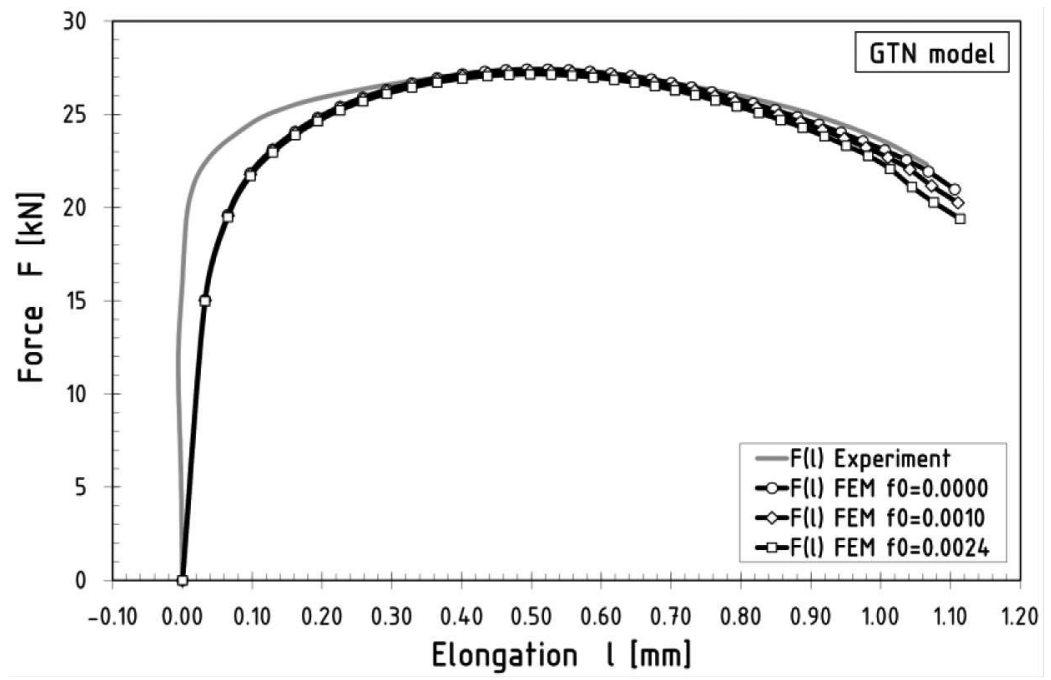

Fig. 7. Force-elongation $F(l)$ curves determined experimentally and numerically using $G T N$ model for $f_{0}=0 \div 0.0024$.

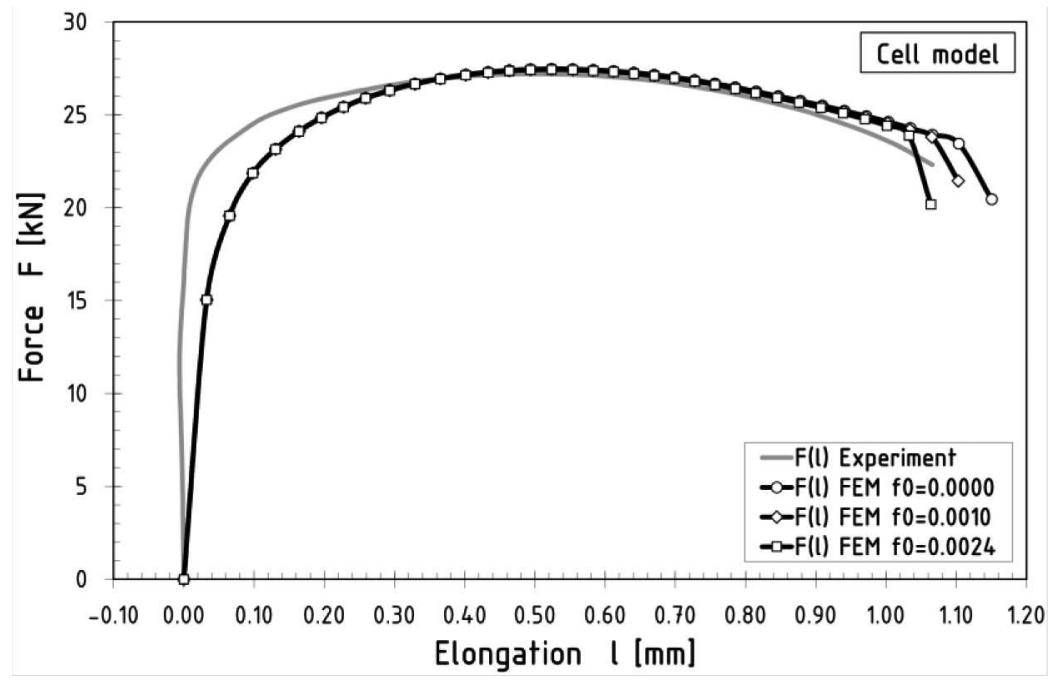

Fig. 8. Force-elongation $F(l)$ curves determined experimentally and numerically using Cell model for $f_{0}=0 \div 0.0024$. 
When GTN model was applied, the differences in forces were growing increasingly above the elongation $l>0.5 \mathrm{~mm}$. They were about $1.0 \%$ for elongation $l=0.5 \mathrm{~mm}$ corresponding to the maximum force for $f_{0}=0$ and $f_{0}=0.0024$. At the failure moment, for elongation $l=1.07 \mathrm{~mm}$, the differences in forces increased up to $8.0 \%$ for $f_{0}=0$ and $f_{0}=0.0024$.

The differences in maximum forces were negligible when Cell model was applied, $0.1 \%$ only for $f_{0}=0$ and $f_{0}=0.0024$. For failure range, visible influence of initial porosity on the material response was noticed. Dependence of the initial void volume fraction on the failure moment is the most important phenomenon observed for assumed porosity of S235JR steel. The failure moment is visible later when material without pores was assumed, i.e. $f_{0}=0$, in comparison to the maximum porosity of tested material, i.e. $f_{0}=0.0024$.

It can be concluded that assuming the fully dense material without pores, i.e. $f_{0}=0$, and the maximum porosity for S235JR steel, i.e. $f_{0}=0.0024$, reveals the visible differences in the material response and load-bearing capacity of the element for both numerical models applied. When average porosity is considered for S235JR steel, i.e. $f_{0}=0.001$, the load-bearing capacity and failure moment is noticed between values observed for two extreme situations described before.

The load-bearing capacity of the elements was strictly connected with the changes in void volume fraction parameter $V V F$ observed during the deformation process of the material. The values of $V V F$ are generally higher in the middle of the element in comparison to the external part of the area adjacent to the fracture plane and thus the initiation of fracture is expected in the middle of the sample. The void volume fraction $V V F$ curves for point in the middle of the fracture plane, on the axis of the sample are shown in Figures 9 and 10.

The beginning of the increase in void volume fraction $V V F$ was depending on the initial porosity assumed. For both numerical models applied, GTN and Cell, the voids grew visible earlier for initial void volume fraction $f_{0}=0.0024$ in comparison to the other values of $f_{0}$ assumed in the study. Consequently, the void growth was noticeably much intensive for $f_{0}=0.0024$.

When using GTN model, the voids increased much rapidly at final, failure range, for $l>1.0 \mathrm{~mm}$. As can be seen in Figure 9, at the failure moment a major difference of $237.7 \%$ was observed in values of $V V F$ parameter for initial void volume fraction $f_{0}=0$ and $f_{0}=0.0024$.

Much rapid increase in the void volume fraction $V V F$ was observed when Cell model was applied for the elongations ranged from $l=1.0 \mathrm{~mm}$ up to $l=1.1 \mathrm{~mm}$, for $f_{0}=0.0024$ and $f_{0}=0$, respectively. Similarly to the forces observed at the failure, also the critical $V V F$ parameters were achieved visible earlier when maximum porosity of the material was assumed, i.e. $f_{0}=0.0024$, in comparison to the fully dense material, i.e. $f_{0}=0$. 


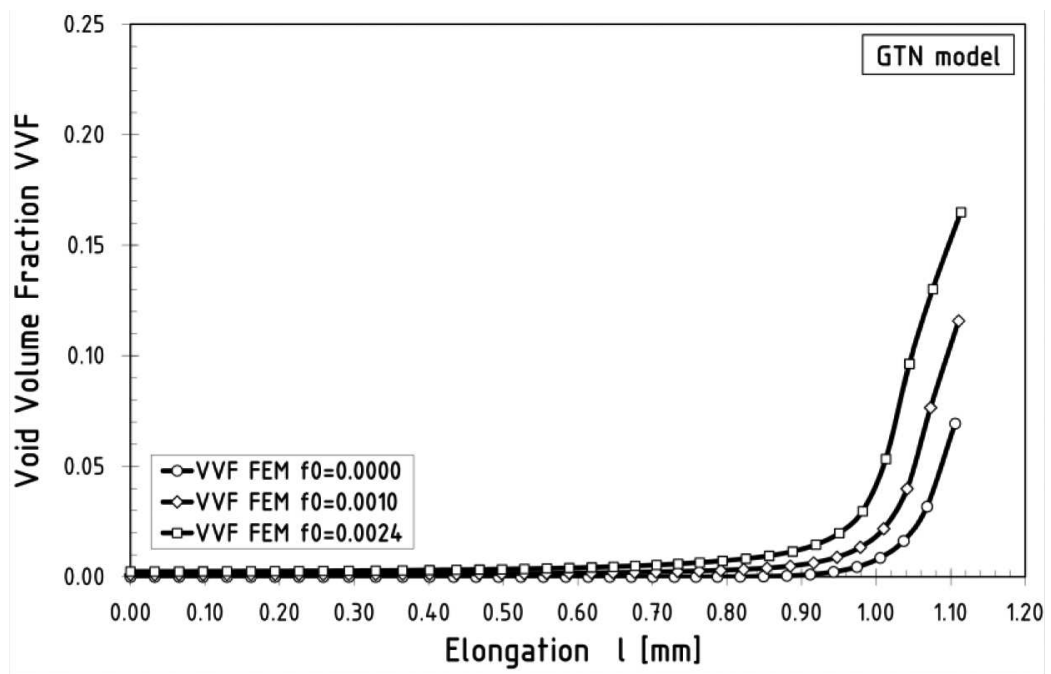

Fig. 9. Void Volume Fraction $V V F$ curves determined numerically using GTN model for $f_{0}=0 \div 0.0024$.

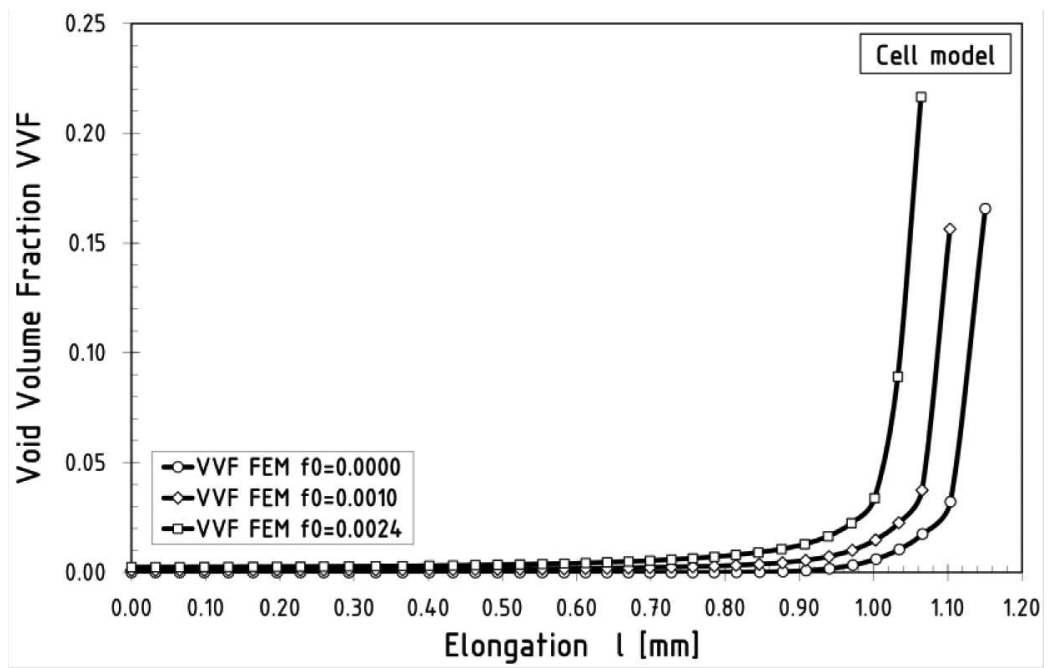

Fig. 10. Void Volume Fraction $V V F$ curves determined numerically using Cell model for $f_{0}=0 \div 0.0024$. 


\section{Discussion}

During the analysis performed, the several characteristic phenomena were observed, which is discussed below.

First of all, the effect of the initial porosity defined by initial void volume fraction $f_{0}$ on the material response under multi-axial stress state at high stress triaxiality $\sigma_{m} / \sigma_{e}=1.345$ for S235JR steel was noticed. This relation was observed for all assumed initial void volume fractions $f_{0}$ at the range corresponding to the two extreme situations of fully dense material without pores and maximum porosity. For both numerical models considered in the study, i.e. non-local GTN and local Cell model, the highest values of forces, i.e. element load-bearing capacity, were noticed when the fully dense material without pores was considered for the initial void volume fraction $f_{0}=0$, and the lowest values of force was noticed for maximum porosity defined by $f_{0}=0.0024$. This is different phenomenon in comparison to the results of the analogous analysis performed at low stress triaxiality, when the material response was negligible affected by initial porosity of S235JR steel [20].

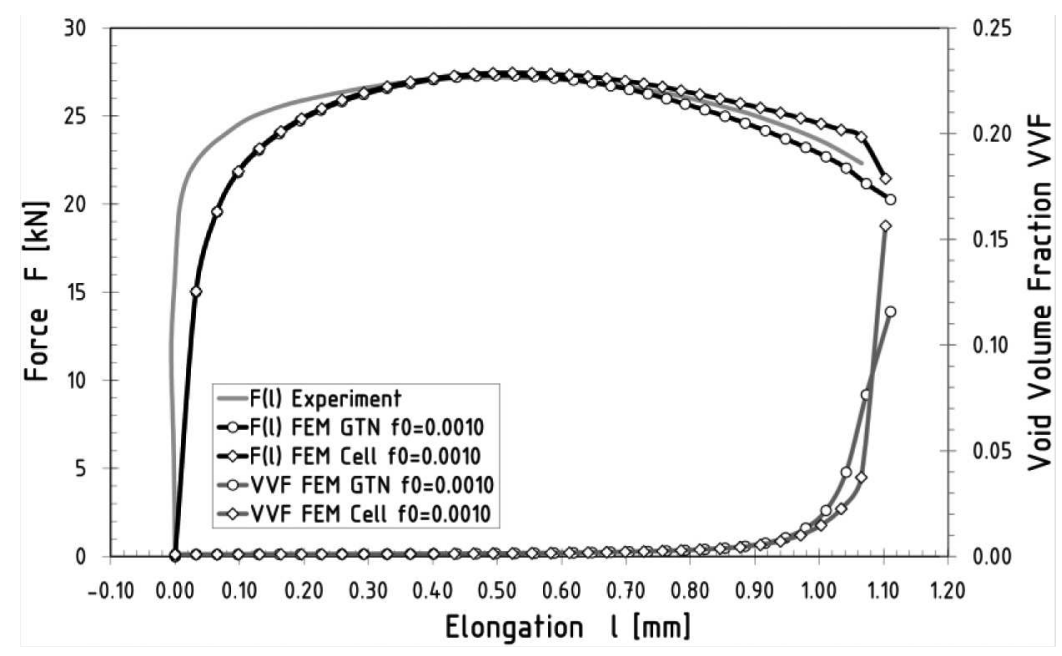

Fig. 11. Force-elongation $F(l)$ and Void Volume Fraction $V V F$ curves determined numerically using GTN and Cell models for $f_{0}=0.001$.

From the engineering point of view it is possible to assume the average value of initial void volume fraction $f_{0}$ for S235JR steel under multi-axial stress states. Much conservative results may be obtain assuming the maximum acceptable initial porosity of tested material which corresponds to the value $f_{0}=0.0024$. The strength curves determined numerically for GTN and Cell models based on the average initial void volume fraction $f_{0}=0.001$ for S235JR steel are shown in Fig. 11. As can be seen, when using GTN model, a slight softening phenomenon is observed. In turn, the application of the Cell model allows to simulate the exact failure moment. 
The influence of initial porosity on void growth is the next observed phenomenon for S235JR steel at high stress triaxiality. For both numerical models the voids grew visible earlier when maximum porosity was assumed, i.e. $f_{0}=0.0024$, in comparison to the other values of $f_{0}$ considered in the study. It resulted in the void growth, which was much intensive for $f_{0}=0.0024$.

Significant differences in values of $V V F$ parameter were noticed when GTN model was used at the failure moment for considered values of $f_{0}$. For $\mathrm{Cell}$ model the critical $V V F$ parameters were achieved visible earlier when maximum porosity of the material was assumed, i.e. $f_{0}=0.0024$, in comparison to the fully dense material, when $f_{0}=0$. These means great impact initial porosity on the void growth in S235JR steel.

\section{Conclusions}

The following conclusions were drawn taking into consideration the results obtained:

1. Generally the effect of the initial porosity defined by initial void volume fraction $f_{0}$ on the material response was noticed for tensile elements under multi-axial stress state at high stress triaxiality $\sigma_{m} / \sigma_{e}=1.345$ for S235JR steel. This effect was especially noticeable at the range of the material failure.

2. The tensile strength curves obtained by applying both GTN and Cell model were consistent with the experimental results in the middle range of deformation, when the maximum force $F$ was reached. The force-elongation $F(l)$ curves obtained numerically for three assumed initial void volume fraction $f_{0}$ were different for both GTN and Cell models applied. For both the models the highest values of forces were noticed when the fully dense material without pores was considered with initial void volume fraction $f_{0}=0$, and the lowest values of force were noticed for maximum porosity defined by $f_{0}=0.0024$.

3. At the failure range in the case of application of the GTN model, the softening phenomenon was noticed in the range above the maximum force $F$. The reverse phenomenon was observed when Cell model was applied, the forces $F$ determined numerically were higher than those obtained during experiments.

4. A great impact of the initial porosity on the void growth for S235JR steel at high stress triaxiality was noticed. For two extreme situations considered, the fully dense material without pores and the maximum porosity of S235JR steel the noticeable differences in changes of void volume fraction in the material were observed.

5. Significant differences in values of $V V F$ parameter were noticed when $G T N$ model was used at the failure moment for considered values of $f_{0}$. For Cell model the critical $V V F$ parameters were achieved visible earlier when maximum porosity of the material was assumed, i.e. $f_{0}=0.0024$, in comparison to fully dense material, i.e. $f_{0}=0$.

6. In terms of load-bearing capacity of the elements, the conservative results were obtained when maximum value of $f_{0}=0.0024$ was used for S235JR steel under 
multi-axial stress state, and this value is recommended to use in the calculations in order to preserve the highest safety of the structure. During usual engineering calculations the average porosity defined by $f_{0}=0.001$ may by applied for S235JR.

\section{REFERENCES}

1. A. BiEgus, D. CzepiżAK, Experimental and numerical studies upon load-bearing capacity of locally strengthened corrugated sheets, Archives of Civil Engineering, 55, 1, 11-28, 2009.

2. A. BIEGUS, D. CZEPIŻAK, Evaluation of resistance of corrugated sheets under bending by a concentrated loads from the local suspensions, Archives of Civil Engineering, 56, 4, 283-297, 2010.

3. P. IwIcki, Sensitivity analysis of buckling loads of bisymmetric $i$-section columns with bracing elements, Archives of Civil Engineering, 56, 1, 69-88, 2010.

4. U. Radoń, Analysis of reliability and stability of bar structures, Archives of Civil Engineering, 56, 2, 155-172, 2010.

5. M. KAmiŃSKi, P. Swita, Reliability modeling in some elastic stability problems via the generalized stochastic finite element method, Archives of Civil Engineering, 57, 3, 275-295, 2011.

6. J. Chróścielewski, M. Rucka, K. Wilde, W. Witkowski, Formulation of spectral truss element for guided waves damage detection in spatial steel trusses, Archives of Civil Engineering, 55, 1, 43-63, 2009.

7. W. Witkowski, M. Rucka, K. Wilde, J. Chróścielewski, Wave propagation analysis in spatial frames using spectral timoshenko beam elements in the context of damage detection, Archives of Civil Engineering, 55, 3, 367-402, 2009.

8. W. Gilewski, M. Sitek, The inf-sup condition tests for shell/plate finite elements, Archives of Civil Engineering, 57, 4, 425-447, 2011.

9. P.W. Bridgman, Studies in large plastic flow and fracture, McGraw-Hill, New York 1952.

10. A.L. Gurson, Continuum theory of ductile rupture by void nucleation and growth: Part I - Yield criteria and flow rules for porous ductile media, Journal of Engineering Materials and Technology, Transactions of the ASME, 99, 1, 2-15, 1977.

11. V. TVergaARD, Influence of voids on shear band instabilities under plane strain conditions, International Journal of Fracture, 17, 4, 389-407, 1981.

12. V. Tvergahd, A. Needleman, Analysis of the cup-cone fracture in a round tensile bar, Acta Metallurgica, 32, 1, 157-169, 1984.

13. A. Needleman, V. Tvergaard, An analysis of the ductile rupture in notched bars, Journal of the Mechanics and Physics of Solids, 32, 6, 461-490, 1984.

14. PN-EN 1993-1-10:2007 Eurocode 3: Design of Steel Structures - Part 1-10: Material Toughness and Through-thickness Properties.

15. G. Sedlacek, M. Feldmann, B. Kühn, D. Tschickardt, S. Höhler, C. Müller, W. Hensen, N. Stranghöner, W. Dahl, P. Langenberg, S. Münstermann, J. Brozetti, J. Raoul, R. Pope, F. BijlaARD, Commentary and Worked Examples to EN 1993-1-10 "Material toughness and through thickness properties" and other toughness oriented rules in EN 1993, JRC Scientific and Technical Reports, European Commission Joint Research Centre, 2008.

16. P.G. Kossakowsкi, An analysis of the load-carrying capacity of elements subjected to complex stress states with a focus on the microstructural failure, Archives of Civil and Mechanical Engineering, 10, 2, 15-39, 2010.

17. P.G. KosSAKowski, W. TRĄMPCZyŃski, Numerical simulation of S235JR steel failure with consideration of the influence of microstructural damages [in Polish], Przegląd Mechaniczny, 4, 15-22, 2011. 
18. P.G. Kossakowski, Simulation of ductile fracture of S235JR steel using computational cells with microstructurally-based length scales, Journal of Theoretical and Applied Mechanics, 50, 2, 589-607, 2012.

19. P. Kossakowski, Simulation of the plastic range of structural steel performance under the complex stress based on the Gurson-Tvergaard-Needleman model, [in Polish], Przegląd Budowlany, 3, 43-49, 2012.

20. P.G. Kossakowski, Influence of initial porosity on strength properties of S235JR steel at low stress triaxiality, Archives of Civil Engineering, 58, 3, 293-308, 2012.

21. A.G. Franklin, Comparison between a quantitative microscope and chemical method for assessment on non-metallic inclusions, Journal of the Iron and Steel Institute, 207, 181-186, 1969.

22. PN-EN 10025-1:2005 Hot Rolled Products of Structural Steels - Part 1: General Technical Delivery Conditions.

23. PN-EN 10002-1:2004 Metallic Materials - Tensile Testing - Part 1: Method of Test at Ambient Temperature.

24. J. Faleskog, X. Gao, C.F. Shin, Cell model for nonlinear fracture analysis - I. Micromechanics calibration, International Journal of Fracture, 89, 4, 355-373, 1998.

25. Aвaqus 6.10 Analysis User's Manual, Dassault Systèmes, Providence 2010.

26. L. Xia, C.F. Sнін, Ductile crack growth - I. A numerical study using computational cells with microstructurally-based length scales, Journal of the Mechanics and Physics of Solids, 43, 2, 233-259, 1995.

27. L. Xia, C.F. Sнiн, Ductile crack growth - II. Void nucleation and geometry effects on macroscopic fracture behavior, Journal of the Mechanics and Physics of Solids, 43, 12, 1953-1981, 1995.

28. X. Gao, J. Faleskog, C.F. Shin, Cell model for nonlinear fracture analysis - II. Fracture-process calibration and verification, International Journal of Fracture, 89, 4, 375-398, 1998.

29. A.M. Kanvinde, G.G. Deierlein, The Void Growth Model and the Stress Modified Critical Strain Model to predict ductile fracture in structural steels, Journal of Structural Engineering, 132, 12, 1907-1918, 2006.

30. J.W. Hancock, A.C. Mackenzie, On the mechanisms of ductile failure in high-strength steels subjected to multi-axial stress-states, Journal of Mechanics and Physics of Solids, 24, 2-3, 147-160, 1976. 